American Journal of Applied Sciences 6 (10): 1826-1830, 2009

ISSN 1546-9239

(C) 2009 Science Publications

\title{
Arsenic Adsorption on Bauxite Mineral Using Batch Equilibrium Test
}

\author{
Fares Yahay Alshaebi, Wan Zuhairi Wan Yaacob, Abdul Rahim Samsudin and Esmail Alsabahi \\ Faculty of Science and Technology, School of Environmental Science and Natural Resources, \\ University Kebangsaan Malaysia, 43600 Bangi, Selangor, Malaysia
}

\begin{abstract}
Problem statement: Study suggested a solution to remove arsenic contamination from contaminated water. Approach: Bauxite, which is a mineral, was proposed as natural remediation material used in this study. Bauxite was collected from Johor mining company in Teluk Ramunia, Johor Bharu, Malaysia. Batch equilibrium test was performed in accordance to different initial concentrations, shaking time and different initial $\mathrm{pH}$ values. Results: Results showed that mineral bauxite has high Cation Exchange Capacity (CEC) and Specific Surface Area (SSA), with the values range from 23.9-32.6 meq/100 g and 18.5-22.09 $\mathrm{m}^{2} \mathrm{~g}^{-1}$, respectively. Sample of bauxite mineral is slightly acidic with $\mathrm{pH}$ values ranging from 5.06-5.35. Percentage of organic matter and carbonate content in bauxite are very low with the values of 3.78-4.57 and 2.435-2.5\% respectively. For batch adsorption, results showed that bauxite has high adsorption capacity for arsenic and it can remove more than $99 \%$ of arsenic from contaminated water. The highest amount of arsenic adsorbed (q) was $4996.6 \mathrm{mg} \mathrm{kg}^{-1}$ in $500 \mathrm{ppm}$ of arsenic concentration after $48 \mathrm{~h}$ of the test in $\mathrm{pH}$ 7.6. The lowest was $4554.7 \mathrm{mg} \mathrm{kg}^{-1}$ in $500 \mathrm{ppm}$ of arsenic at $24 \mathrm{~h}$ of shaking time in $\mathrm{pH} 10$. Conclusion: Results indicated that bauxite can be used as a natural material for the removal of arsenic from contaminated water.
\end{abstract}

Key words: Arsenic, bauxite, batch test, sorption

\section{INTRODUCTION}

Arsenic, atomic number 33, is located in the periodic table directly below phosphorus. Arsenic is considered a metalloid and occurs in a variety of forms and oxidation states. The two oxidation states common in drinking water are arsenate, $\mathrm{As}(\mathrm{V})$ and arsenite, $\operatorname{As}(\mathrm{IIII})^{[1]}$.

Arsenic and its compounds are mobile in the environment. Weathering of rocks converts arsenic sulfides to arsenic trioxide, which enters the arsenic cycle by dissolution in rain, rivers, or groundwater or as dust. Arsenic cycle (Fig. 1) occurs among land, air and water after the liberation of arsenic from rocks and soil. Volatile forms of arsenic enter the atmosphere from land and water and then they are returned by rain or atmospheric fallout. The oxidized forms of arsenic are reduced back to sulfides under anaerobic conditions on land and water sediments ${ }^{[2]}$.

Economic geologists have a long-standing interest in arsenic because gold and arsenic are strongly correlated in many deposits. For this reason and the relatively low concentration of arsenic in most crustal rocks, prospectors use arsenic as a pathfinder element when exploring for gold. This strong association also explains why mining industries are a major source of arsenic waste and mine sites are major sources of arsenic to the wider environment. The arsenic bearing minerals in ore deposits are usually stable over geologic time in their undisturbed environment. The disturbance to the natural environment from mining and mineral processing often leaves arsenic in a less stable state, which creates opportunities for off-site transport, usually by water ${ }^{[3]}$.

Arsenic is considered to be an essential element, but many arsenic compounds are known to be toxic. Due to the carcinogenicity of some arsenic compounds, regulatory agencies have established the maximum contaminant level for arsenic in drinking water. The objective is to reduce arsenic exposure to a level as close to zero as possible, considering its health effects and toxicology, occurrence, human exposure, feasibility of the treatment technology, availability of analytical techniques to quantify the lower levels of arsenic and estimated risk for cancer as a consequence of long term exposure $^{[4]}$.

The World Health Organization (WHO) recommended arsenic level to $10 \mu \mathrm{g} \mathrm{L}^{-1}$ and in 2002,

Corresponding Author: Fares Yahay Alshaebi, Faculty of Science and Technology,

School of Environmental Science and Natural Resources, University Kebangsaan Malaysia, 43600

Bangi, Selangor, Malaysia 
EPA published a revised standard to set the new MCL for arsenic at $10 \mu \mathrm{g} \mathrm{L}^{-1[5,6]}$.

Bauxite is a naturally occurring, heterogeneous material composed primarily of one or more aluminium hydroxide minerals, plus various mixtures of silica, iron oxide, titania, aluminosilicate and other impurities in minor or trace amounts. The principal aluminium hydroxide minerals found in varying proportions with bauxites are gibbsite and the polymorphs boehmite and diaspore. Bauxites are typically classified according to their intended commercial application: Abrasive, cement, chemical, metallurgical, refractory. The bulk of world bauxite production (approximately 85\%) is used as feed for the manufacture of alumina via a wet chemical caustic leach method commonly known as the Bayer process. Subsequently, the majority of the resulting alumina produced from this refining process is in turn employed as the feedstock for the production of aluminium metal by the electrolytic reduction of alumina in a molten bath of natural or synthetic cryolite $\left(\mathrm{Na}_{3} \mathrm{AlF}_{6}\right)$, the Hall-Héroult process ${ }^{[7]}$.

This study presents the physical-chemical characterization of bauxite and its effectiveness to remove arsenic from contaminated water via batch equilibrium test with different concentration, $\mathrm{pH}$ and interaction time.

\section{MATERIALS AND METHODS}

Bauxite mineral was used in this study as a removal material for Arsenic contamination. The samples were collected from Teluk Ramunia mine in Johor bharu south part of Malay Peninsula. Bauxite sample was subjected to three main tests; i.e., (i) physical-chemical tests and (ii) sorption tests via batch equilibrium tests. The physical tests were specific Gravity (Gs), compaction and water content. While the chemical tests were Cation Exchange Capacity (CEC) which uses ammonium acetate, Specific Surface Area (SSA) which uses EGME method and pH measurement.

The sorption experiment was used to study the effect of three factors (initial concentrations, shaking time and different $\mathrm{pH}$ of arsenic). The batch procedure was also reported by Wan Zuhairi ${ }^{[10-12]}$. Four grams of bauxite sample were weighed into the centrifuge tubes with $40 \mathrm{~mL}$ of arsenic contaminant mixed for $24 \mathrm{~h}$ for different stock solutions at different concentrations, i.e., 5, 10, 20, 50, 100, 200, 300, 400 and 500 ppm. Different $\mathrm{pH}$ values of the stock solution were used in this study, i.e., 2, 3, 4, 5, 6, 7, 8, 9 and 10. The tubes were then shaken at different shaking times from 1, 5, 10, 20, 40, $60,90,120,360,720,1440$ until $2880 \mathrm{~min}$. After it reached equilibrium stage, the tube was centrifuged at
1000-2000 Revelation Per Minute (RPM). The solutions yielded were sent for analysis using Inductively Coupled Plasma Mass Spectroscopy (ICP-MS).

The arsenic that left in the solution was used to calculate the amounts which adsorbed by the bauxite. The sorption isotherms for all bauxite samples were plotted between the amounts of arsenic species removed from solution per gram of mineral sample, $\mathrm{q}$ in $\left(\mathrm{mg} \mathrm{kg}^{-1}\right)$ and as solute, $\mathrm{C}$ in $\left(\mathrm{mg} \mathrm{L}^{-1}\right)$. The values of $\mathrm{q}$ were calculated using the equation below:

$$
q=\frac{V_{w}\left(C_{o}-C_{i}\right)}{M_{\text {sed }}}
$$

Where:

$\mathrm{q}=$ The amount of the metal absorbed per mass unit of solid $\left(\mathrm{mg} \mathrm{kg}^{-1}\right)$

$\mathrm{C}_{\mathrm{o}}$ and $\mathrm{C}_{\mathrm{i}}=$ The arsenic concentration in the initial solution and after the reaction time in the filtrate, respectively $\left(\mathrm{mg} \mathrm{L}^{-1}\right)$

$\mathrm{V}_{\mathrm{w}} \quad=$ The volume of solution added $(\mathrm{mL})$

$\mathrm{M}_{\text {sed }} \quad=$ The air-dried mass of bauxite $(\mathrm{g})$

\section{RESULTS}

Table 1 summarized the physical and chemical properties of bauxite mineral. The values of optimum moisture content (W\%) is ranging from 24.4-26. Results showed that bauxite has slightly low specific gravity values ranging from 2.43-2.65 due to the relatively higher gibbsite and lower iron contents. The dry density and maximum density are ranging from $1.49-1.55$ and $1.86-1.9$, respectively. The porosity is $43-45.5 \%$. The samples have low clay content ranging from $5-9 \%$. The $\mathrm{pH}$ of bauxite was slightly acidic with the value of ranging from 5.06-5.35. Results showed that bauxite has slightly low specific gravity values range from $2.43-2.65$ due to the relatively higher gibbsite and lower iron contents.

Table 1: The physico-chemical properties

\begin{tabular}{ll}
\hline Parameters & Bauxite \\
\hline $\mathrm{W}(\%)$ & $24.4-26$ \\
$\mathrm{Gs}$ & $2.43-2.65$ \\
$\gamma_{\mathrm{d}}\left(\mathrm{g} \mathrm{cm}^{-3}\right)$ & $1.49-1.55$ \\
$\gamma_{\max }\left(\mathrm{g} \mathrm{cm}^{-3}\right)$ & $1.86-1.9$ \\
Porosity $(\%)$ & $43-45.5$ \\
Clay $(\%)$ & $5-9$ \\
$\mathrm{pH}$ & $5.06-5.35$ \\
$\mathrm{SSA}\left(\mathrm{m}^{2} \mathrm{~g}^{-1}\right)$ & $18.5-22.09$ \\
$\mathrm{CEC}\left(\mathrm{meq}^{-1} / 100 \mathrm{~g}\right)$ & $23.9-32.6$ \\
$\mathrm{OM}(\%)$ & $3.78-4.57$ \\
$\mathrm{CC}(\%)$ & $2.43-2.5$ \\
XRD & $\mathrm{Gb}>\mathrm{K}$
\end{tabular}

Gb: Gibbsite, K: Kaolinite, W (\%): Water content, Gs: Specific gravity, $\gamma_{\mathrm{d}}$ : Dry density, $\gamma_{\max }$ : Maximum density, SSA: Specific Surface Area, CEC: Cation Exchange Capacity, OM: Organic Matter, CC: Carbonate Content 
Am. J. Applied Sci., 6 (10): 1826-1830, 2009

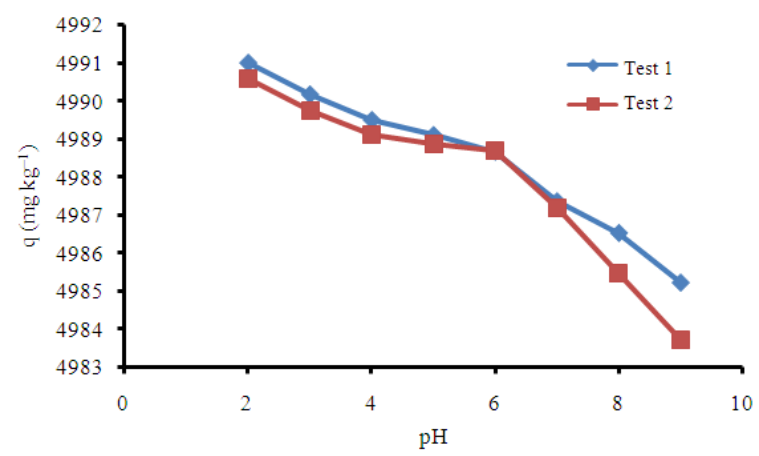

Fig. 1: Arsenic removal from contaminated solution with different $\mathrm{pH}$ from an initial concentration of $500 \mathrm{ppm}$

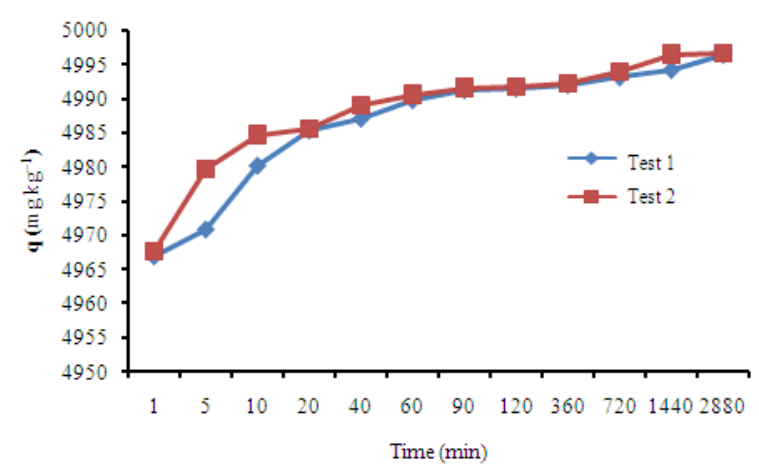

Fig. 2: Arsenic removal from contaminated solution with different shaking time from an initial concentration of $500 \mathrm{ppm}$

Figure 2 represents the effect of contact time (1$2880 \mathrm{~min}$ ) of arsenic adsorption on bauxite. The kinetic test was performed to investigate the effect of time on adsorption of arsenic. Increasing of the shaking time helps mineral bauxite to remove the largest amount of arsenic. The highest value of the adsorbed arsenic was $4996.8 \mathrm{mg} \mathrm{kg}^{-1}$ after $48 \mathrm{~h}$ of shaking which means that $99.9 \%$ of the arsenic was removed. The lowest value was $4966.95 \mathrm{mg} \mathrm{kg}^{-1}$, i.e., $99.3 \%$ of arsenic removed after $1 \mathrm{~min}$ shaking. It is noted that the removal of arsenic increases with time. The results of removal and percentage of removal are shown in Fig. 2.

Sorption of arsenic by bauxite at different initial concentrations showed that the sorption of arsenic increased with the increase of initial concentrations. The removal percentage of arsenic was $99.23 \%$ at initial concentration of $20 \mathrm{ppm}$, while $99.83 \%$ of arsenic was removed from the initial concentration of $300 \mathrm{ppm}$. Brief results are shown in Table 4 and Fig. 3. This result gives the impression that the adsorption of arsenic by bauxite is not affected by the arsenic concentration.

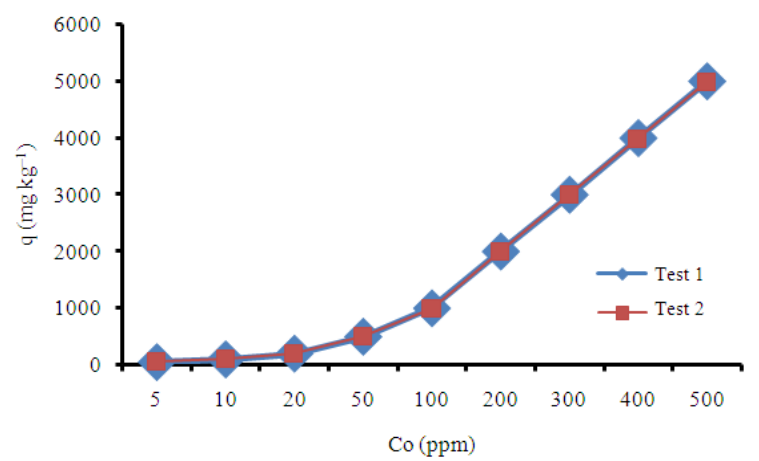

Fig. 3: Arsenic removal from contaminated solution with different initial concentration

Table 2: The percentage of Arsenic removal at different $\mathrm{pH}$ values

\begin{tabular}{ll}
\hline $\mathrm{pH}$ & Arsenic removal (\%) \\
\hline 2 & 99.82 \\
3 & 99.80 \\
4 & 99.78 \\
5 & 99.78 \\
6 & 99.77 \\
7 & 99.74 \\
8 & 99.73 \\
9 & 99.70 \\
10 & 91.09 \\
\hline
\end{tabular}

Table 3: The percentage of Arsenic removal at different shaking time

\begin{tabular}{ll}
\hline Time $(\mathrm{min})$ & Arsenic removal $(\%)$ \\
\hline 1 & 99.34 \\
5 & 99.42 \\
10 & 99.60 \\
20 & 99.72 \\
40 & 99.78 \\
60 & 99.80 \\
90 & 99.83 \\
120 & 99.84 \\
360 & 99.85 \\
720 & 99.88 \\
2840 & 99.88 \\
\hline
\end{tabular}

Table 4: Total arsenic removal with different initial concentration

\begin{tabular}{ll}
\hline Initial concentration & Arsenic removal (\%) \\
\hline 5 & 99.71 \\
10 & 99.28 \\
20 & 99.23 \\
50 & 99.54 \\
100 & 99.76 \\
200 & 99.81 \\
300 & 99.83 \\
400 & 99.78 \\
500 & 99.78 \\
\hline
\end{tabular}

\section{DISCUSSION}

Because the result of X-Ray Diffraction (XRD) showed that most of the clay mineral is gibbsite, so it is commonly characterized by a comparatively low specific 
gravity value of about 2.40 , while the iron minerals are characterized by higher specific gravity values ranging from 3.20-5.26 depending on the type of iron minerals ${ }^{[8]}$.

Cation Exchange Capacity (CEC) result showed bauxite has high adsorption capacity. The sorption capacity of mineral increases with the increasing value of cation exchange ${ }^{[9]}$. Besides, it was found that the Specific Surface Area (SSA) values ranging from 18.5$22.09 \mathrm{~m}^{2} \mathrm{~g}^{-1}$. These results strengthen the capacity of the mineral adsorption of contamination. The sorption capability of the bauxite increases with the increasing values of CEC and SSA ${ }^{[10-13]}$. Bauxite sample has low carbonate content. According to Yong ${ }^{[12]}$ carbonate content in soil will lower down the values of SSA. Bauxite contain has a high proportion of gibbsite which improve the sorption of contaminated ${ }^{[9]}$.

The effect of arsenic $\mathrm{pH}$ on bauxite sorption is shown in Fig. 1. The $\mathrm{pH}$ is an important factor affecting the removal of arsenic from aqueous solution. The results show that arsenic adsorption capacity was higher when the $\mathrm{pH}$ was acidic compared with $\mathrm{pH}$ was alkaline. Where the highest adsorption value of arsenic was $4991 \mathrm{mg} \mathrm{kg}^{-1}$ in the first test and $4990.56 \mathrm{in} \mathrm{sec}$ tests at $\mathrm{pH} 2$ which refers to that more than $99.8 \%$ of arsenic was removed. However, above $\mathrm{pH} 3$ there was a slight decreased in uptake of arsenic to $4988 \mathrm{mg} \mathrm{kg}^{-1}$ at $\mathrm{pH} 6$ and further reduced to 4554 at $\mathrm{pH} 10$. As it is clear from Fig. 1, the removal of arsenic is consistent in a wide $\mathrm{pH}$ range of 2-6 indicating that arsenic is effectively adsorbed by bauxite. Xu et al. ${ }^{[16]}$ reported that at $\mathrm{pH}$ range "between" 3-6 arsenic ion occurs mainly in the form of $\mathrm{H}_{2} \mathrm{AsO}_{4}{ }^{-}$whereas, the divalent anion $\mathrm{HAsO}_{4}{ }^{2-}$ dominates at higher $\mathrm{pH}$ of 8-10. Also in the intermediate $\mathrm{pH}$ range of 6-8, both species co-exist.

The adsorption mechanism at $\mathrm{pH}$ range 3-6 may be due to binding of the arsenic species to the available partially positive surfaces ${ }^{[14,15]}$. Whereas, the decrease in the adsorption yields above $\mathrm{pH} 6$ may be attributed to the increasing electrostatic repulsion between the negative surface sites and the negative arsenic species. Bahakat $e a{ }^{[14]}$ found that consistency over a wide $\mathrm{pH}$ range gives bauxite an edge for its practical application in drinking water treatment.

In addition, kinetic test showed that bauxite have high capacity to adsorption of arsenic and the adsorption increase with the increasing of shaking time. This result gives the impression that the adsorption of arsenic by bauxite is not affected by the arsenic concentration.

\section{CONCLUSION}

The results from this study revealed that bauxite is a potential adsorbent for arsenic removal from the aqueous environment. Bauxite mineral has suitable physical and chemical properties such as high values of CEC and SSA, resulting high adsorption capacity that make bauxite as a potential natural material to remove arsenic from contaminated water. It is also discovered that bauxite mineral can remove $99.93 \%$ of arsenic from contaminated water.

\section{REFERENCES}

1. Brandhuber, P. and G. Amy, 1998. Alternative methods for membrane filtration of arsenic from drinking water. Desalination, 117: 1-10. DOI: 10.1016/S0011-9164(98)00061-7

2. Pontius, F.W., K.G. Brown and C.J. Chen, 1994. Health implications of arsenic in drinking water. J. Am. Water Works Assoc., 86: 52-63. http://cat.inist.fr/?aModele=afficheN\&cpsidt=4251866

3. Charles, F.H. and D.B. Roger, 2005. Arsenic: Its Biogeochemistry and Transport in Groundwater in Metal Ions in Biological Systems. In: Biogeochemistry, Availability and Transport of Metals in the Environment, Astrid, S., S. Helmut and K.O.S. Roland (Eds.). Informa Health Care, New York, ISBN: 0849338204, pp: 145-169.

4. Viraraghavan, T., K.S. Subramanian and J.A. Aruldoss, 1999. Arsenic in drinking water-problems and solutions. Water Sci. Technol., 40: 69-76. DOI: 10.1016/S0273-1223(99)00432-1

5. Ning, R.Y., 2002. Arsenic removal by reverse osmosis. Desalination, 143: 237-241. DOI: 10.1016/S0011-9164(02)00262-X

6. Chwirka, J.D., C. Colvin, J.D. Gomez and P.A. Mueller, 2004. Arsenic removal from drinking water using the coagulation/microfiltration process. Am. Water Works Assoc., 96: 106-114. http://cat.inist.fr/?aModele $=$ afficheN\&cpsidt $=15602222$

7. Zone, M. 2005. Bauxite Information. http://www.mineralszone.com/minerals/bauxite.html

8. Li, L.Y. and G.K. Rutherford, 1996. Effect of bauxite properties on the settling of red mud. Int. J. Mineral Procss., 48: 169-182. http://cat.inist.fr/?aModele $=$ afficheN\&cpsidt $=2546238$

9. Sharma, H.D. and K.R. Reddy, 2004. Geoenvironmental Engineering: Site Remediation, Waste Containment and Emerging Waste Management Technologies. 1st Edn., Willy, ISBN: 10: 0471215996, pp: 992.

10. Wan Zuhairi, W.Y., 2003. Sorption capacity on lead, copper and zinc by clay soils from South Wales, United Kingdom. Environ. Geol., 45: 236-242. http://cat.inist.fr/?aModele $=$ afficheN\&cpsidt $=1543$ 5826 
11. Wan Zuhairi, W.Y., 2003. Heavy metal sorption capabilities of some soil samples from active landfill sites in Selangor. Geologic. Soc. Malaysia Bull., 46: 295-297.

12. Wan Zuhairi, W.Y. and S. Abdul Rahim, 2007. Sorption Parameters of $\mathrm{Pb}$ and $\mathrm{Cu}$ on Natural Clay Soils from Selangor, Malaysia. Sains Malaysian, 36: 149-157.

13. Yong, R.N., 2000. Geoenvironmental Engineering Contaminated Soils, Pollutant Fate and Mitigation. 1st Edn., CRC Press, New York, ISBN: 10: 0849382890, pp: 320.

14. Bhakat, P.B., A.K. Gupta, S. Ayoob and S. Kundu, 2006. Investigations on arsenic $(\mathrm{V})$ removal by modified calcined bauxite. Colloids Surfaces A: Physicochem. Eng. Aspects, 281: 237-245. http://cat.inist.fr/?aModele $=$ afficheN\&cpsidt $=1780$ 3507
15. Debasish, M., M. Debaraj and P.K. Ho, 2008. A laboratory scale study on arsenic (V) removal from aqueous medium using calcined bauxite ore. J. Environ. Sci., 20: 683-689. DOI: 10.1016/S10010742(08)62113-0

16. Xu, Y.H., T. Nakajima and A. Ohki, 2002. Adsorption and removal of $\operatorname{arsenic}(\mathrm{V})$ from drinking water by aluminum-loaded Shirasuzeolite. J. Hazard. Mater., 92: 275-287. 